\title{
Ecumenical Alethic Pluralism
}

Filippo Ferrari (University of Bonn) \& Sebastiano Moruzzi (University of Bologna)

\begin{abstract}
Ecumenical Alethic Pluralism (EAP) is a novel kind of alethic pluralism. It is ecumenical in that it widens the scope of alethic pluralism by allowing for a normatively deflated truth property alongside a variety of normatively robust truth properties. We establish EAP by showing how Wright's Inflationary Arguments fail in the domain of taste, once a relativist treatment of the metaphysics and epistemology of that domain is endorsed. EAP is highly significant to current debates on the nature of truth insofar as it involves a reconfiguration of the dialectic between deflationists and pluralists.
\end{abstract}

Keywords: truth; pluralism; deflationism; relativism; inflationary argument; normativity; taste

\section{Introduction}

Alethic pluralism-roughly, the thesis that truth amounts to different properties in different domains - comes in a variety of forms. ${ }^{1}$ Taking truth to be a normative (and thus inflationary) property is common to virtually all ${ }^{2}$ known versions of pluralism. This is owing to two arguments offered by Crispin Wright, known as Inflationary Arguments (henceforth IAs), ${ }^{3}$ which aim to show that since truth functions as a distinctive norm, it thereby has a normative, and thus inflationary, nature. Although the IAs play a central strategic role for truth pluralists, there are surprisingly few critical discussions of them.

\footnotetext{
${ }^{1}$ See Wright (2013).

${ }^{2}$ Some authors advocate non-inflationary truth pluralism. Beall (2013) develops deflationary pluralism in reply to paradoxes. Kölbel 2013 cites questionnaires to support the idea that people deploy two distinct truth concepts: one inflationary, the other non-inflationary. These are non-domain-based pluralisms, and thus differ significantly from EAP. See Barnard \& Ulatowski (forthcoming) for data concerning the empirical adequacy of a domain-based alethic pluralism with a non-inflationary truth.

${ }^{3}$ Wright (1992, unpublished manuscript).
} 


\section{Forthcoming in the Canadian Journal of Philosophy}

Our objective in this paper is twofold. First, we critically assess Wright's IAs. We show how a local counterexample can be construed by developing a subjectivist and relativist metaphysical and epistemological framework, pertaining to the domain of basic taste. ${ }^{4}$ This provides us with what is needed to block the IAs in that domain. We argue that the local failure of the IAs does not entail that they are globally unsuccessful: in some domains, where the metaphysics and epistemology we develop for taste does not apply, the IAs go through. This establishes what we call Alethic Dualism, the view that there are two distinct truth properties: a non-normative truth property in the domain of taste (and possibly others), and a normative truth property applying elsewhere. Second, once alethic dualism is on board we work our way towards an ecumenical form of pluralism. By means of what is known as the scope problem for monistic inflationary accounts of truth, ${ }^{5}$ we argue that there are at least two normative truth properties. This delivers a wider form of pluralism than those already present in the literature. Specifically, it is a form of pluralism in which we have a non-normative truth property operating (at least) in the domain of taste alongside a plurality of normative truth properties that operate elsewhere. We call this view Ecumenical Alethic Pluralism (EAP).

The structure of this paper is as follows. In section 2, we examine Wright's IAs. Section 3 provides a subjectivist and relativistic epistemology and metaphysics of taste. In sections 4 and 5, we develop our strategies for blocking the IAs within the domain of taste. Section 6 discusses the significance of our counterexample to IAs vis-à-vis alethic pluralism. Finally, sections 7 and 8 introduce ecumenical alethic pluralism, locating it within the current debate on truth pluralism.

\section{The two anti-deflationary arguments}

\footnotetext{
${ }^{4}$ We focus on basic taste judgements, e.g., "this sushi is delicious". For simplicity, we will omit 'basic' from now on. ${ }^{5}$ Lynch (2009).
} 


\section{Forthcoming in the Canadian Journal of Philosophy}

Most philosophers agree that judgement is governed by norms. ${ }^{6}$ Nevertheless, there is disagreement about what these norms consist in and moreover how to formulate them. In discussing Wright's IAs, we assume that both truth and justification ${ }^{7}$ are norms of judgement. They both provide criteria for the correctness of the formation, maintenance, and rejection of judgements. The questions at the core of the IAs are whether truth and justification provide the same or distinct norms, and, if distinct, what accounts for truth's normative function. Wright's conclusion is threefold: (i) truth and justification mark distinct norms of judgement; (ii) truth's normative function is a feature of its nature; (iii) qua normative property, truth plays an explanatory role vis-à-vis the core phenomena of enquiry.

The IAs are intended to apply globally (i.e., to all truth-apt domains), targeting those deflationary views sharing the following set of commitments: function; propositionality; exhaustion; abundance; and non-normativity. ${ }^{8}$ According to function, truth is a device for expressing indirect endorsement of a claim or collection of claims. Propositionality refers to the thesis that propositions are the primary truth-bearers. According to exhaustion, all facts whose expression involves truth can be explained by assuming nothing more than (non-pathological) instances of the Equivalence Schema (ES):

(ES) $\langle\mathrm{p}\rangle$ is true if and only if $\mathrm{p}$.

According to abundance, truth is a genuine property, that is, 'true' functions in language as a meaningful predicate. As such, it refers to a genuine property. Finally, non-normativity is the thesis that truth's nature isn't normative.

\footnotetext{
${ }^{6}$ See Chan (2013).

${ }^{7}$ We focus on propositional justification.

${ }^{8}$ We take Horwich (1998) to be a paradigmatic example of a view endorsing these commitments.
} 


\section{Forthcoming in the Canadian Journal of Philosophy}

Wright's IAs purport to show that truth qualifies as inflationary. This is because truth has a normative nature - i.e., it marks a sui generis norm of judgement — contributing to an explanation of the core phenomena of enquiry. We argue that counterexamples can be found to IAs in the domain of taste. This means that a non-normative option is available, albeit only locally. This leaves open whether the IAs go through in other domains. In fact, we argue that they do.

\subsection{Wright's first inflationary argument (IA1)}

IA1 has two stages. ${ }^{9}$ Stage one establishes that truth and justification coincide in positive normative force by first noticing that a reason to regard a proposition as justified is a reason to endorse it as a belief, and conversely. Second, a reason to endorse a proposition as a belief is, by (ES), a reason to regard the proposition as true, and conversely. Thus, a reason to regard a proposition as justified is a reason to regard it as true, and conversely. ${ }^{10}$ This establishes that truth and justification, qua norms of judgement, coincide in positive normative force. That is to say, in judging that $\langle\mathrm{p}\rangle$, a subject, in taking herself to comply with the truth norm, thereby takes herself to comply with the justification norm (and vice versa).

A legitimate question at this point is the following: in virtue of what is truth normative? Given the normative coincidence just observed, a reasonable answer would be to say that truth is normative in virtue of justification's being normative-i.e., truth's normative character is inherited from the normative character of justification. However, this answer faces an objection, which leads to the second stage of the argument. Clearly, a belief can be justified without being true, and it can

\footnotetext{
${ }^{9}$ Wright (1992). We offer our own reconstruction of the arguments.

${ }^{10}$ Wright $(1992,18)$.
} 


\section{Forthcoming in the Canadian Journal of Philosophy}

be true without being justified. Formally, while 'true' commutes with negation, 'justified' does not.

Thus, the following equivalence holds for truth: ${ }^{11}$

(NE) $\langle\mathrm{p}\rangle$ is not true if and only if $\langle$ not $p>$ is true.

However, an analogous principle of justification (NE-J) fails from the left-to-right direction:

(NE-J) $\langle p>$ is not justified if and only if $\langle$ not-p $>$ is justified.

This failure is owing to the possibility of epistemically neutral states of information:

(Epistemic Neutrality) A subject, $\mathrm{S}$, is in an epistemically neutral informational state, $i$, with respect to $\langle\mathrm{p}>$ just in case $i$ provides $\mathrm{S}$ with neither a justification for $\langle\mathrm{p}>$ nor a justification for $\langle$ not-p $\rangle$.

Relative to a neutral state of information, both $\langle p\rangle$ and $\langle$ not-p $\rangle$ fall outside the extension of 'justified'. If either $<\mathrm{p}>$ or $<$ not-p $>$ fall within the extension of 'true', we can infer that truth and justification potentially diverge in extension. Thus, whereas the extension of 'justified' is potentially gappy in that, for some $\langle p\rangle$, neither $\langle p>$ nor its negation falls within its extension, this is not the case for truth. 'True' and 'justified' potentially diverge in extension. Let us call this Normative Divergence.

In sum, according to IA1: (i) truth and justification function as norms governing judgement; (ii) they coincide in terms of positive normative force; (iii) however, they signal two distinct norms owing to their potential divergence in extension; (iv) this means that truth's normative character is not inherited from that of justification; (v) thus, truth's normative character marks a distinctive feature of truth; (vi) owing to its sui generis normative nature, truth contribute explaining some

\footnotetext{
${ }^{11}$ We ignore the possibility of a truth-value gap for $p$ - see Wright (1992, 61-4) for discussion. To meet intuitionistic anxieties, NE can be reformulated as the principle that (necessarily) it is not the case that neither $p$ nor not- $p$ are in the in the extension of the truth-property.
} 


\section{Forthcoming in the Canadian Journal of Philosophy}

normative phenomena at the core of our practice of enquiry. For instance, truth contributes to the explanation of, for example, the appropriateness of praising whoever judges truly, and criticising whoever endorses an untrue judgement. Moreover, as Price (1998) argues, truth's normative nature is what grounds the possibility of a certain kind of objective disagreement - as opposed to a mere difference of opinion. In virtue of these explanatory functions, the argument aims to conclude that truth's normative character inflates truth's nature.

\subsection{Wright's second inflationary argument (IA2)}

A structurally similar argument, hinging on the defeasible character of justification, establishes a second potential divergence based on the thought that justification, but not truth, can be lost through time. While a past or future tense claim ${ }^{12}$ - e.g., that $\mathrm{p}$ was/will be the case - cannot be true at a time unless the claim about the embedded (say, present tense, for simplicity) proposition is true at an earlier/later time, this does not hold generally for justification. The justification for past/future tense claims can fail even if there is a justification for the embedded proposition at an earlier/later time.

To illustrate: at $\mathrm{t}_{1}$, Jülide is justified in believing the true proposition, $\langle\mathrm{p}\rangle$, that Elias is the murderer on evidence, $e$, but at a later time, $\mathrm{t}_{2}$, she acquires new evidence, $e^{*}$, showing that $e$ is misleading and thus defeats Jülide's previous justification for $\left\langle\mathrm{p}>\right.$. Thus, at $\mathrm{t}_{2}$, relative to evidence $\mathrm{e}^{*}$, it is false that Jülide, at $\mathrm{t}_{1}$, was justified in believing $\langle\mathrm{p}\rangle$, even though, as a matter of fact, $\langle\mathrm{p}\rangle$ was and remains true.

According to Wright, there are core principles connecting the truth-values of differentlytensed judgments made at different times. He calls these truth-value links: ${ }^{13}$

$$
\text { (fut/pres-T) } \forall \mathrm{t}_{1}\left[\left(\mathrm{~T}_{[\mathrm{t} 1]}(\mathrm{Will}: \mathrm{p})\right) \text { iff } \exists \mathrm{t}_{2}\left(\mathrm{t}_{2}>\mathrm{t}_{1}\right)\left(\mathrm{T}_{[\mathrm{t} 2]}(\mathrm{p})\right)\right]
$$

\footnotetext{
${ }^{12}$ We assume that "it will be the case that p" and "it was the case that p" express, respectively, the propositions that it will be the case that $\mathrm{p}$ and that it was the case that $\mathrm{p}$.

${ }^{13}$ An earlier discussion of the truth-value links can be found in Wright (1993).
} 


\section{Forthcoming in the Canadian Journal of Philosophy}

(past/pres-T) $\forall \mathrm{t}_{2}\left[\left(\mathrm{~T}_{[\mathrm{t} 2]}(\right.\right.$ Was:p) $)$ iff $\left.\exists \mathrm{t}_{1}\left(\mathrm{t}_{1}<\mathrm{t}_{2}\right)\left(\mathrm{T}_{[\mathrm{t} 1]}(\mathrm{p})\right)\right]$

The corresponding principles connecting justification and tensed judgments would be the following:

$$
\begin{array}{ll}
\text { (fut/pres-J) } & \forall \mathrm{t}_{1}\left[\left(\mathrm{~J}_{[\mathrm{t} 1]}(\mathrm{Will}: \mathrm{p})\right) \text { iff } \exists \mathrm{t}_{2}\left(\mathrm{t}_{2}>\mathrm{t}_{1}\right)\left(\mathrm{J}_{[\mathrm{t} 2]}(\mathrm{p})\right)\right] \\
\text { (past/pres-J) } & \forall \mathrm{t}_{2}\left[\left(\mathrm{~J}_{[\mathrm{t} 2]}(\mathrm{Was}: \mathrm{p})\right) \text { iff } \exists \mathrm{t}_{1}\left(\mathrm{t}_{1}<\mathrm{t}_{2}\right) \quad\left(\mathrm{J}_{[\mathrm{t} 1]}(\mathrm{p})\right)\right]
\end{array}
$$

where "J $\mathrm{J}_{[\mathrm{t}]}(\mathrm{p})$ " means that $\mathrm{p}$ is justified at time $t$, analogously " $\mathrm{T}_{[\mathrm{t}]}(\mathrm{p})$ " means that $\mathrm{p}$ is true at time $t$, and "Was:p", "Will:p" mean, respectively, that it was the case that $\mathrm{p}$ and that it will be the case that p.

Wright discusses the divergence between truth and justification with respect to both future and past tense taste judgments. We focus only on past tense taste judgments-i.e., we consider only the past/pres T- and J-links, which we will call, hereon, "T-link" and "J-link", respectively. Parallel arguments can be given in relation to future tense judgments about taste.

Since justification is relative to states of information, we rephrase the (past/pres-J) principle by doubly relativizing justification to informational states and times. One subject is justified at time $t$ given the evidence available to her at the informational state $k$ in believing that it was the case that $\mathrm{p}$, just in case at an earlier time and informational state $i$ she was justified in believing that $\mathrm{p}$ on the basis of the evidence in $i$. The amended J-link reads:

$$
(\mathrm{J}-\text { Link }) \quad \forall \mathrm{t}_{2}, k\left[\left(\mathrm{~J}_{[\mathrm{k}, \mathrm{t} 2]}(\mathrm{Was}: \mathrm{p})\right) \leftrightarrow \exists \mathrm{t}_{1}, i\left(\mathrm{t}_{1}<\mathrm{t}_{2}\right)\left(\mathrm{J}_{[\mathrm{i}, \mathrm{t} 1]}(\mathrm{p})\right)\right]
$$

Wright argues that whereas either direction of the J-Link can fail-since justification can be improved or defeated - this is not the case for the T-link. To see this, consider the following diachronic divergence lemmas (DDLs):

(DDL-1) $\exists i, k \exists t_{2, t_{1}}\left(t_{2}>t_{1}\right):\left[\mathrm{J}_{[\mathrm{i}, \mathrm{t} 1]}(\mathrm{p}) \& \mathrm{~T}_{[\mathrm{t} 1]}(\mathrm{p}) \& \mathrm{~T}_{[\mathrm{t} 2]}(\mathrm{Was}: \mathrm{p}) \&\right.$ not-J $\left.\mathrm{J}_{[\mathrm{k}, \mathrm{t2}]}(\mathrm{Was}: \mathrm{p})\right]$.

(DDL-2) $\exists i, k \exists t_{2, t_{1}}\left(t_{2}>t_{1}\right):\left[\mathrm{J}_{[\mathrm{k}, \mathrm{t} 2]}(\mathrm{Was}: \mathrm{p}) \& \mathrm{~T}_{[\mathrm{t} 1]}(\mathrm{p}) \& \mathrm{~T}_{[\mathrm{t} 2]}(\mathrm{Was}: \mathrm{p}) \& \operatorname{not}-\mathrm{J}_{[\mathrm{i}, \mathrm{t} 1]}(\mathrm{p})\right]$. 


\section{Forthcoming in the Canadian Journal of Philosophy}

These DDLs establish a contrast between two norms of belief rejection, one imposed by truth and the other by justification:

(T-Rejection) A subject S's rejection of a previously accepted proposition $<\mathrm{p}>$ is correct only if $\langle p\rangle$ is false.

(J-Rejection) A subject S's rejection at $t$ of a previously accepted proposition $\langle\mathrm{p}\rangle$ is correct only if S's informational states $i$ at $t$ contains (temporarily undefeated) evidence that defeats (either by overriding or by undermining) the justification $\mathrm{S}$ previously possessed for $\langle\mathrm{p}\rangle$.

J-rejection requires Jülide to reject her judgment because the evidence on which it was based is undermined by her new evidence. By contrast, T-rejection predicts that she ought not reject her previous judgment because true. Conversely, we might have a situation where a subject ought to reject a judgment because false even though, by following J-rejection, she wouldn't have to reject it because her justification remains undefeated. This reinforces the conclusion that truth has a distinctive normative nature, concurring with the explanation of the core normative phenomena of enquiry associated with judgement, rejection, and disagreement.

\section{Subjectivism and relativism about taste}

To locally block both IAs, we outline a subjectivist and relativist metaphysics and epistemology of taste according to which: (i) taste properties-e.g., being tasty - and the justification for taste judgements are fully grounded in the subject (subjectivism); and (ii) any change in the subject's gustatory experience makes a difference with respect to the instantiation of a taste property and to the availability of justification (relativism).

\subsection{Metaphysics of taste}




\section{Forthcoming in the Canadian Journal of Philosophy}

Our metaphysics of taste has two core aspects: (i) metaphysical subjectivism, i.e., the thesis that the instantiation of taste properties - e.g., the property of being tasty — entirely depends on the tastes of the beholder; (ii) metaphysical relativism, i.e., the thesis that different beholders with different tastes give rise to different facts about what is (and is not) tasty.

According to metaphysical subjectivism, the instantiation of a taste property fully depends on the gustatory responses (GRs) of the subject. This amounts to a form of response dependence. In what follows, we focus on the properties of tastiness and distastefulness that we take to be paradigmatic cases for, respectively, positive and negative (basic) gustatory evaluations. According to response-dependence, whether a given gustatory object possesses a taste property entirely depends on the pleasurable/unpleasant responses of the subject to her gustatory experience of that object.

The second component of our metaphysics of taste is metaphysical relativism. What taste facts there are is entirely determined by the set of gustatory responses of a subject. Alterations in the subject, or changes in her gustatory responses, engender a change in the world of taste-conceived as a triplet including a world, time, and subject. As a consequence, the extension of a taste property is relative to the world of taste of a subject. Reality is thus composed of two sorts of facts: objective facts-e.g., facts about the physical composition of objects, whose occurrence is independent of any subject's perspective - and perspectival facts — e.g., taste facts — which cannot be apprehended from a bird's-eye view, and therefore whose occurrence depends on a particular perspective. ${ }^{14}$ Which taste facts obtain is a matter that can only be established once one is immersed in a perspective. ${ }^{15}$

\footnotetext{
14 The totality of taste-facts relative to a subject constitutes her world of taste.

15 Our metaphysical relativism is related to Fine's external relativism. See Fine (2005, 278-84). See also Einheuser (2008), and Spencer (2016).
} 


\section{Forthcoming in the Canadian Journal of Philosophy}

These two theses are mutually supportive. Metaphysical relativism safeguards metaphysical subjectivism from contradiction: given two subjects with different gustatory responses, a taste property can consistently be instantiated and not instantiated by the same object since it is always relative to a subject irrespective of whether the object has that property. Metaphysical subjectivism endorses metaphysical relativism since it grounds the relativity predicted by metaphysical relativism. According to metaphysical subjectivism, the subject's gustatory experiences and responses shape the subject's perspective on the world of taste: different perspectives involve different true propositions about taste—and thus different taste facts.

Our metaphysics of taste can be expressed by the following relativized form of response dependence:

(RRD) $x$ is tasty/distasteful relative to a world of taste $\langle w, s, t\rangle$ if and only if (because) $x$ produces at $t$ in $w$ a gustatory experience $\mathrm{P}$ with a certain phenomenological quality $\square$ (e.g., pleasantness or unpleasantness) in $\mathrm{S}$ such that $\mathrm{P}$ engenders, in the absence of any disabling factor, a pleasurable/unpleasant response in the subject at $t$ in $w$.

RRD gives us an alternative to a thoroughgoing realist conception of taste by offering a model that, while being compatible with classical semantics and allowing for taste properties existing in the world, it rejects the thought that their instantiation is an absolute, mind-independent matter. ${ }^{16}$

We are aware that RRD has an unintuitive drawback: it predicts that any gustatory object of which a subject has had no experience falls within the anti-extension of every taste property (e.g., it is not-tasty, not-disgusting, etc.) relative to the subject. However, notice that saying an object falls within the anti-extension of a gustatory property (e.g., being tasty) does not mean that it falls within the extension of any of its contrary properties (e.g., being distasteful). In order for an object to fall

\footnotetext{
${ }^{16}$ See Ferrari and Moruzzi (forthcoming) for a version of (RRD) compatible with non-classical semantics.
} 


\section{Forthcoming in the Canadian Journal of Philosophy}

within the extension of being distasteful relative to a subject, the subject must have had a displeasing response to it. One way of assuaging the unpalatableness of this drawback is suggested by Williamson (1997, 223-26). The idea is that the negation of an atomic predicate is maximally unspecific, that is, it is uncommitted to anything specific about the object to which it applies. This introduces an asymmetry between the instantiation of an atomic property and the instantiation of its negation: when nothing grounds the application of an atomic property to an object, the object remains maximally unspecific with respect to that property and it thus falls within its anti-extension instead of neither falling in the extension nor in the anti-extension.

\subsection{Epistemology of taste}

There are two components to our epistemology of taste: (i) epistemic subjectivism - the thesis that the justification for a taste proposition consists in and is exhausted by the subject's GRs to her experience; and (ii) epistemic relativism - the thesis that what counts as evidence for a taste proposition varies according to the GRs of the subject.

In characterizing epistemic subjectivism, we idealise the epistemic condition of a subject S.

First, we assume that there is an a priori justification for RRD available to S. Second, we assume that $\mathrm{S}$ has epistemic access to those parts of her informational state that are relevant to her gustatory experiences. If $\mathrm{S}$ has a gustatory experience with a specific phenomenological quality (either positive, negative, or neutral), she thereby has justification to believe that she had such an experience with that quality. Moreover, if she has no experience, she will have justification to believe that she has had no experience. We thus endorse the following principles:

(PAGE) Positive Accessibility of Gustatory Experience: if S has a gustatory experience of $x$ with a certain phenomenological quality $\square$, then $S$ has justification to believe that she has had such an experience of $x$ with quality $\square$. 


\section{Forthcoming in the Canadian Journal of Philosophy}

(NAGE) Negative Accessibility of Gustatory Experience: if S has no gustatory experience of $x$, then $\mathrm{S}$ has justification to believe that she has had no gustatory experience of $x .^{17}$

Epistemic subjectivism is in harmony with the thesis that the only source of justification for a taste proposition is first-personal gustatory experience. We can call this the primacy of experience thesis. This excludes from the set of sources of justification other grounds, such as testimony, in full agreement with the so-called acquaintance principle, ${ }^{18}$ according to which evidence for a judgement about taste must be acquired through first-hand experience and cannot be transmitted from person to person.

The second component of our epistemology of taste is epistemic relativism: what counts as evidence for a taste proposition is relative to a subject's epistemic perspective at a particular time. The epistemic perspective encompasses, but is not limited to, the subject's GRs at t. Call 's' a particular piece of sushi. Whether or not a justification for $\langle\mathbf{s}$ is tasty $>$ is available to a subject is a matter relative to the subject's gustatory responses at a certain time: if two different times involve different gustatory responses - e.g., the subject has first, at time $\mathrm{t}_{1}$, a pleasant response and then, at a later time $\mathrm{t}_{2}$, an unpleasant response - then $\left\langle\mathbf{s}\right.$ is tasty $>$ is justified for that subject relative to $\mathrm{t}_{1}$ but unjustified relative to $t_{2}$.

The relativistic component to the epistemology of taste is not just another way of cashing out the subjectivist thesis. Epistemic subjectivism allows that whether or not one's GRs dictate that the food is tasty is an absolute epistemic fact that can be appreciated by any epistemic agent. What epistemic relativism calls into question is precisely the idea of absolute epistemic facts about taste

\footnotetext{
17 These principles impose a transparency condition on gustatory experience in relation to justification. Williamson (2000, 24-7) defines transparency in relation to knowledge. We are committed to holding that the mental state of having a gustatory experience is transparent. However, it is not obvious that it is plausible to assume, as Williamson (2000, ch.4) does in his anti-luminosity argument for the experience of cold, that a series of indiscriminable differences in the supervenience base of basic taste properties can produce a sorites-like sequence for gustatory experiences.

${ }^{18}$ See Wollheim (1980).
} 


\section{Forthcoming in the Canadian Journal of Philosophy}

propositions. Call $s$ a particular piece of sushi. If my GRs to sushi provide a justification for $<\mathbf{s}$ is tasty>, then even if my previous GRs were different this would not now count as evidence for the fact that I was justified in believing that sushi is not tasty: relative to my informational state, what counts as evidence for $<\mathbf{s}$ is tasty $>$ is entirely determined by the information compatible with my current GRs.

A detached point of view on matters of taste is thus excluded. Since a subject either has had or has not had an experience of the relevant food, she determines both the extension of the tasteproperty — via RRD and the primacy of experience — and the justificatory status of the relevant taste proposition. Call this feature perspectival immersion.

\section{How to block IA1}

IA1 relies on the possibility of neutral states of information. The features of the metaphysics and epistemology of taste discussed above provide a basis for arguing against the possibility of epistemic neutrality in the domain of taste. Thus, IA1 fails locally.

Notice, first, that there are two potential sources of epistemic neutrality: ${ }^{19}$ i) phenomenological neutrality, which occurs when a subject has a gustatory experience with a qualitative aspect engendering in the subject a neutral response (of neither pleasure nor displeasure); ii) radical neutrality, which occurs when a subject has no gustatory experience whatsoever of a particular gustatory object. We argue that neither source gives rise to epistemic neutrality in the domain of taste.

\footnotetext{
${ }^{19}$ Note that both the absence of a gustatory experience and the presence of a pleasant experience are sufficient conditions for enforcing the negation of the left-hand-side of RRD. The production of a contrary experience (distastefulness), or the absence of any experience, are conditions that are incompatible with the right-hand-side of RRD-i.e., with the existence of a pleasant experience.
} 


\section{Forthcoming in the Canadian Journal of Philosophy}

Phenomenological neutrality occurs when a subject has had a gustatory experience of an object with a phenomenologically neutral character. Consider again our example of sushi $\mathbf{s}$ and suppose $\mathrm{S}$ is in an informational state $i$ such that she has a phenomenologically neutral experience of $\mathbf{s}$. Because the response is not pleasant, via RRD, we can claim that $\mathbf{s}$ lacks the property of tastiness. If we assume that $\mathrm{S}$ has an a priori justification at $i$ for RRD, and moreover that she can introspect her gustatory experiences in order to obtain justification at $i$ such that she believes she has a phenomenologically neutral experience (via PAGE), then, via closure of justification under logical consequence, we obtain that $\mathrm{S}$ has justification at $i$ to believe that $\mathbf{s}$ isn't tasty. Thus, if $\mathrm{S}$ is in an informational state $i$ of phenomenological neutrality with respect to $\mathbf{s}$, she has justification at $i$ for $\langle\mathbf{s}$ is not tasty $>$, which is incompatible with being in a state of epistemic neutrality.

Radical neutrality obtains in cases of absolute lack of gustatory experience of s. Assume that $\mathrm{S}$ is at $\mathrm{t}$ in a state of radical neutrality $i$ with respect to $\mathbf{S}$. According to NAGE, $\mathrm{S}$ is at $\mathrm{t}$ justified in believing that she has had no gustatory experience of $\mathbf{s}$ if, in fact, she has had no gustatory experience of $\mathbf{s}$ at that time. Radical neutrality and NAGE thus entail that at $\mathrm{t} \mathrm{S}$ has justification at $i$ and $t$ for the negation of the right-hand-side of RRD. Call this latter fact $J$-Absence. Assuming that $S$ has a justification at $i$ for RRD, it follows, by closure of justification under logical consequence and $\mathrm{J}$ Absence, that $\mathrm{S}$ at $\mathrm{t}$ has a justification at $i$ for $<\mathbf{s}$ is not tasty $>$, which is incompatible with being in a state of epistemic neutrality. ${ }^{20}$

Thus, our framework excludes the possibility that a subject can be in a state of epistemic neutrality in the taste domain. This is regardless of whether its putative source is radical or phenomenological neutrality. No normative divergence between truth and justification has been established in the taste domain.

\footnotetext{
${ }^{20}$ These arguments can be generalized to taste properties (e.g., being distastefulness).
} 


\section{Forthcoming in the Canadian Journal of Philosophy}

\section{How to block IA2}

IA2 is purported to show that truth is a normative property because it marks distinctive norms of acceptance and rejection targeting future- and past-tensed judgements. As for IA1, the inflationary significance of IA2 has to do with the potential extensional divergence between truth and justification in virtue of their different normative roles. We challenge the soundness of the divergence lemmas in the taste domain. To recap, the principles in play in IA2 are:

$$
\begin{array}{ll}
(\mathrm{T}-\text { Link }) & \forall \mathrm{t}_{2}\left[\left(\mathrm{~T}_{[\mathrm{t} 2]}(\text { Was:p })\right) \leftrightarrow \exists \mathrm{t}_{1}\left(\mathrm{t}_{1}<\mathrm{t}_{2}\right)\left(\mathrm{T}_{[\mathrm{t} 1]}(\mathrm{p})\right)\right] \\
(\mathrm{J}-\text { Link }) & \forall \mathrm{t}_{2}, k\left[\left(\mathrm{~J}_{[\mathrm{k}, \mathrm{t} 2]}(\text { Was:p) }) \leftrightarrow \exists \mathrm{t}_{1}, i\left(\mathrm{t}_{1}<\mathrm{t}_{2}\right)\left(\mathrm{J}_{[\mathrm{i}, \mathrm{t} 1]}(\mathrm{p})\right)\right]\right.
\end{array}
$$

A possible divergence in extension between truth and justification can be established because, while the T-Link always holds, the J-link fails in both directions. On the one hand, we have the possibility of defeaters, "because new information overrides or undermines an earlier warranted assertion about a then contemporaneous situation". ${ }^{21}$ On the other hand, retrospective discoveries are possible, "because it might happen that we acquire a warrant for thinking that something was earlier so for which there was no evidence at the time". ${ }^{22}$ We refute these two putative directions of failure of the J-link in relation to taste propositions.

Let us first examine the left-to-right direction of the J-link. The ground for its failure is given by the possibility of retrospective discoveries (DDL-2). Consider the specific sample of sushi $\mathbf{s}$. There is a time $\mathrm{t}_{2}$ and an informational state $i$ in which the subject acquires justification at $i$ for $<$ Was: $\mathbf{s}$ is tasty $>$ even though at no time $\mathrm{t}_{1}$ earlier than $\mathrm{t}_{2}$ and informational state $k$ there is justification available to the subject for $<\mathbf{s}$ is tasty $>$. Given the primacy of experience, the only way to acquire justification for $<\mathbf{s}$ is tasty $>$ is through direct gustatory experience. A justification for <Was: $\mathbf{s}$ is

\footnotetext{
${ }^{21}$ Wright (unpublished manuscript).

22 Ibid.
} 


\section{Forthcoming in the Canadian Journal of Philosophy}

tasty $>$ at $\mathrm{t}_{2}, i$, then, has to be grounded in a justification for $<\mathbf{s}$ is tasty $>$ that the subject had at some earlier time and informational state. Thus, no present evidence can give the subject a first-time justification for a past-taste proposition. Therefore, we have no failure of the right-to-left direction of the J-Link - and thus no witness to DDL-2.

Let us examine the right-to-left direction of the J-link. The ground for its failure is that whereas justification is defeasible, truth is not. This leads to the first Diachronic Divergence Lemma:

$$
\text { (DDL-1) } \exists \mathrm{i}, k \exists t_{2, t_{1}}\left(t_{2}>t_{1}\right):\left[\mathrm{J}_{[\mathrm{i}, \mathrm{t} 1]}(\mathrm{p}) \& \mathrm{~T}_{[\mathrm{t} 1]}(\mathrm{p}) \& \mathrm{~T}_{[\mathrm{t} 2]}(\mathrm{Was}: \mathrm{p}) \& \operatorname{not}-\mathrm{J}_{[\mathrm{k}, \mathrm{t} 2]}(\mathrm{Was}: \mathrm{p})\right]
$$

Whereas the truth of $\langle\mathrm{p}\rangle$ at a time $\mathrm{t}_{1}$ is a ground for the truth of $\langle$ Was: $\mathrm{p}\rangle$ at a later time $\mathrm{t}_{2}$, a ground for the justification of $\langle\mathrm{p}\rangle$ at $\mathrm{t}_{1}, i$ can fail to be a ground for the justification of $\langle$ Was: $\mathrm{p}\rangle$ at a later time $\mathrm{t}_{2}$ and informational state $k$. This is because at $\mathrm{t}_{2}$ a defeater targeting the justification of $\langle\mathrm{p}\rangle$ is acquired.

A defeater for $\langle\mathrm{p}\rangle$ is a piece of $\mathrm{p}$-relevant information that precludes justifiably believing $\langle p\rangle$. There are two types of defeaters: i) overriders, defeaters for $\langle p\rangle$ whose effect is that of providing direct evidential support for some other proposition $\langle q\rangle$, such that $\langle q\rangle$ if and only if $\langle$ not$\mathrm{p}\rangle$; ii) underminers, defeaters for $\langle\mathrm{p}\rangle$ whose effect is that of providing evidence that undercuts either the source of justification for $\langle p\rangle$, or the evidence-acquiring methods employed by the subject in support of $\langle p\rangle$, without providing direct epistemic support for $\langle$ not-p $\rangle$. We first consider the effect of overriders and then that of underminers on the left-to-right direction of the J-link. We argue that in both cases this direction of the J-link does not fail for taste propositions.

\subsection{Case 1: Overriders}

Suppose a subject $\mathrm{S}$ tastes $\mathbf{S}$ at $\mathrm{t}_{1}$ and informational state $i$, finding it tasty. She acquires a justification for $<\mathbf{s}$ is tasty $>$ at $\mathrm{t}_{1}, i$ - let's call the latter proposition $S U S H I$. At a later time $\mathrm{t}_{2}$ and informational state $k, \mathrm{~S}$ comes to know that $\mathbf{S}$ was prepared in poor hygienic conditions thus provoking disgust in 


\section{Forthcoming in the Canadian Journal of Philosophy}

her. This information has the putative effect of overriding S's justification for SUSHI. There are two relevant scenarios: (i) such information is acquired absent of any concurrent gustatory experience of $\mathbf{s}$; (ii) the information is acquired while tasting $\mathbf{s}$ again. In the first scenario, given the primacy of experience, such information is epistemically irrelevant to the gustatory assessment of s. When acquired in isolation from any concurrent gustatory experience of $\mathbf{s}$, such information does not succeed in overriding the justification for SUSHI that S acquired through gustatory experience. What such information does achieve, nevertheless, is to defeat the implicit presupposition that the food was prepared in standard hygienic conditions. Although this does not per se defeat our justification for the judgement that $\mathbf{s}$ is delicious, it might preclude our right to claim it. Therefore, this case does not offer a counterexample to the J-link. If, however, such information is acquired when $\mathrm{S}$ undergoes a new gustatory experience of $\mathbf{s}$, then, because the sense of disgust is associated with the particular qualitative aspect engendered by her current gustatory experience of $\mathbf{s}$, such a piece of information would have epistemic relevance. Does it count as an overrider for the justification $\mathrm{S}$ had at $\mathrm{t}_{1}, i$ for SUSHI capable of sustaining DDL-1? We argue that it doesn't.

Suppose that $i$ is the informational state that $\mathrm{S}$ has at $\mathrm{t}_{1}$ in relation to $S U S H I$ and that $k$ is an extension of $i$ at $\mathrm{t}_{2}$ such that it provides an overrider for SUSHI:

[1] $\mathbf{J}_{[i, t 1]}(\mathrm{SUSHI}) \&$ not-J ${ }_{[k, t 2]}($ Was:SUSHI) (Assumption)

Every fact about taste is perspectival—we express this by means of the operator “@ $\mathrm{S}_{\mathrm{t}}$ ”. Thus, $<@ \mathrm{~S}_{\mathrm{t}}$ $\mathrm{p}>$ is the proposition that $<\mathrm{p}>$ holds relative to S's taste perspective at $t$. The @-operator can be placed in front of a proposition-e.g., $<@ \mathrm{~S}_{\mathrm{t}} \mathrm{SUSHI}>$, which is the proposition that $<\mathrm{SUSHI}>$ holds from S's taste perspective at $t$ - but it can also be placed in front of truth-value ascriptions relativized to times-e.g., $\left.\left\langle @ \mathrm{~S}_{\mathrm{t} 2} \mathrm{~T}_{[\mathrm{t} 1]}(<\mathrm{SUSHI}\rangle\right)\right\rangle$, which is the proposition that $\langle\mathrm{SUSHI}\rangle$ is true relative to $\mathrm{t}_{1}$ from $\mathrm{S}$ 's taste perspective at $\mathrm{t}_{2}$. Assume that at $\mathrm{S}$ 's taste perspective at $\mathrm{t}_{1}<\mathrm{SUSHI}>$ is true at $\mathrm{t}_{1}$ : 


\section{Forthcoming in the Canadian Journal of Philosophy}

[2] @ $\mathrm{S}_{\mathrm{t} 1} \mathrm{~T}_{[\mathrm{t} 1]}(<\mathrm{SUSHI}>)$ (Assumption)

Suppose further that the overrider is given by the change of taste experienced by $\mathrm{S}$ at $\mathrm{t}_{2}$ :

[3] @ $\mathrm{S}_{\mathrm{t} 2} \mathrm{~S}$ 's experiences of $\mathbf{s}$ changes so that $\mathrm{S}$ doesn't have a pleasant GR to $\mathbf{s}$ anymore (Assumption)

Given RRD, S's world of taste changes in tandem with her gustatory responses, and the extension of the property of tastiness (TASTY) varies accordingly, no longer including $\mathbf{s}$ :

[4] @ $\mathrm{S}_{\mathrm{t} 2}$ the extension of TASTY changes (RRD:3)

Hence, given the change of extension of TASTY, in the world of taste individuated by S's taste at $\mathrm{t}_{2}$, it is no longer true, relative to $\mathrm{t}_{2}$, that $\mathbf{s}$ is tasty:

[5] @ $\mathrm{S}_{\mathrm{t} 2}$ not- $\mathrm{T}_{[\mathrm{t} 2]}(<\mathrm{SUSHI}>)(4)$

Moreover, the perspectival immersion feature entails that the ground for the truth of $<$ SUSHI $>$ relative to $t_{1}$ is irrelevant from the point of view of the world of taste individuated by $S$ 's taste at $t_{2}$ :

[6] @ $\mathrm{S}_{\mathrm{t} 2}$ the change of $\mathrm{S}^{\prime} \mathrm{s}$ GRs reshapes the world of taste $\mathrm{S}$ so as to make the positive experience that $\mathrm{S}$ had at $\mathrm{t}_{1}$ irrelevant for the determination of the extension of TASTY (Metaphysical Relativism: 4)

Hence, given the change of extension of TASTY, in the world of taste individuated by S's taste at $\mathrm{t}_{2}$, it is no longer true, relative to $\mathrm{t}_{1}$, that $\mathbf{s}$ is tasty:

[7] @ $\mathrm{S}_{\mathrm{t} 2} \operatorname{not}-\mathrm{T}[\mathrm{t} 1](<\mathrm{SUSHI}>)(6)$ 


\section{Forthcoming in the Canadian Journal of Philosophy}

Given the T-link this is tantamount to saying that:

[8] @ $\mathrm{S}_{\mathrm{t} 2}$ not-T[t2] $(<\mathrm{Was}: \mathrm{SUSHI}>)(\mathrm{T}-\mathrm{Link}: 7)$

Given epistemic relativism, S's taste perspective impacts on the epistemic significance of a piece of information. The change of taste that $\mathrm{S}$ undergoes at $\mathrm{t}_{2}, k$, also makes irrelevant what, in the world of taste of $\mathrm{t}_{1}, i$ constituted a justification for believing <SUSHI $>$ :

[9] @ $\mathrm{S}_{\mathrm{t} 2}$ the change of subject's GRs reshapes S's world of taste thus making the gustatory experience with a pleasant phenomenological character that $S$ has at $t_{1}$ irrelevant for the justification at $\mathrm{t}_{2}$ for $<$ SUSHI $>$ (Epistemic Relativism: 3 ).

This is to say:

$[10] @ \mathrm{~S}_{\mathrm{t} 2}$ not-J $\mathrm{J}_{[\mathrm{i}, \mathrm{t} 1]}(<\mathrm{SUSHI}>)(9)$

Therefore, the presence of an overrider at $\mathrm{t}_{2}$ does not support DDL-1.

Strictly speaking, line 1 of the argument has to be rewritten using the @-operator, and since there is no world of taste where line 1 holds, there is no world of taste where there is an overrider. This fact generalizes: in no world of taste do we have a witness to DDL-1-i.e., at no time do we have a situation sustaining a divergence between truth and justification. Notice that the T-Link fails at no time-i.e., in no world of taste. We only have cross-time/world failures of the T-Link (lines 7 \& 2). Analogously, the J-Link fails at no time-i.e., in no world of taste. We only have crosstime/world failures of the J-Link - the fact that at $\mathrm{t}_{2}$, not- $\mathrm{J}_{[\mathrm{k}, \mathrm{t} 2]}(<\mathrm{Was}: \mathrm{SUSHI}>)$ and the fact that at $\mathrm{t}_{1}, \mathrm{~J}_{[i, 11]}(<\mathrm{SUSHI}>)$. Thus, at no time - from within a world of taste — can a divergence between truth and justification occur, since failures of either links can occur only at different times involving 


\section{Forthcoming in the Canadian Journal of Philosophy}

different taste worlds. However, owing to metaphysical relativism, two facts belonging to different worlds do not constitute a (conjunctive) fact, since worlds of taste are, as it were, insulated. Cases of inter-world divergence cannot provide a witness for DDL-1, nor for the failure of the T-link.

\subsection{Case 2: Underminers}

Let's consider the effect of underminers on the right-to-left direction of the J-Link. We discuss two cases: the pill case and the ginger case.

Suppose that at $\mathrm{t}_{1} \mathrm{~S}$ tastes $\mathbf{S}$ and has a pleasant response. Thus, $\mathrm{S}$ at $\mathrm{t}_{1}$ is in an informational state $i$ that justifies $\langle$ SUSHI $\rangle-$ i.e., $<$ s is tasty $\rangle$. Moreover, assume that $\langle$ SUSHI $\rangle$ is true relative to $t_{1}$ and suppose that at $t_{2} S$ comes to know that at $t_{1}$ she was under the effect of a pill that altered her physiology by interfering with the phenomenological character of her previous gustatory experience. Let's add this potentially undermining information to S's informational state $k$ at $\mathrm{t}_{2}$. What happens to the justification of <Was:SUSHI $>$ ? If that additional information were to work as an underminer, the result would be that $\mathrm{S}$ lacks justification for $<$ Was:SUSHI $>$ relative to $t_{2}$ and informational state $k$. However, this is not what happens. Given the primacy of experience, the information that $\mathrm{S}$ is under the effect of the pill has no epistemic consequence for the justification of both $<$ SUSHI $>$ and $<$ Was:SUSHI $>$. What matters, epistemically, is merely that the original gustatory experience of $\mathbf{s}$ at $\mathrm{t}_{1}$ which, if pleasant, gives the subject a justification for $\langle\mathrm{SUSHI}\rangle$ and also for $\langle$ Was:SUSHI $\rangle$ provided, ex hypothesi, that the subject undergoes no other gustatory experience between $\mathrm{t}_{1}$ and $\mathrm{t}_{2}$.

Consider now the ginger case. Suppose that $S$ at $t_{1}$ tastes $\mathbf{S}$ with a pair of chopsticks which, unbeknownst to her, were used to eat ginger, leaving the chopsticks with a residue of ginger $\mathbf{g}$. In tasting $\mathbf{s}$, contaminated with $\mathbf{g}, \mathbf{S}$ has an unpleasant gustatory experience, and thus she judges that $\mathbf{s}$ is distasteful - call $N-S U S H I$ the proposition $<\mathbf{s}$ is distasteful $>$. Later, at $\mathrm{t}_{2}$, she comes to know that someone used the chopsticks to eat ginger. She thereby rejects her previous judgment since she 


\section{Forthcoming in the Canadian Journal of Philosophy}

realizes she now lacks justification for thinking that $\mathbf{s}$ wasn't tasty. Does this case bear witness to DDL-1? We do not think so since, while we have—not- $\mathrm{J}_{[\mathrm{k}, \mathrm{t2}]}(<\mathrm{Was}: \mathrm{N}-\mathrm{SUSHI}>)$ — we lack$\mathrm{J}_{[\mathrm{i}, \mathrm{t} 1]}(<\mathrm{N}-\mathrm{SUSHI}>)$. This is because the object of taste at $\mathrm{t}_{1}$ was the composed object $\mathbf{s}+\mathbf{g}-\mathrm{i}$.e., sushi plus ginger piece - and not $\mathbf{s}$ alone. The proposition (call it $N-G U S H Y$ ) for which she has a justification at $\mathrm{t}_{1}$ is thus $<\mathbf{s}+\mathbf{g}$ is distasteful $>-\mathrm{J}_{[\mathrm{i}, \mathrm{t} 1]}(<\mathrm{N}-\mathrm{GUSHI}>)$. Thus, no witness of DDL-1 is forthcoming, which means that no divergence lemma can be sustained invoking an underminer.

To summarize, we have shown two things. First, given our epistemic relativism in tandem with the primacy of experience we cannot have genuine overriders. Typically, the way overriders work requires the coexistence within the same informational state of two competing pieces of information: the original evidence supporting $\langle p\rangle$, and the defeating evidence supporting some $\langle q\rangle$, semantically incompatible with $\langle\mathrm{p}\rangle$. However, given the primacy of experience, nothing but gustatory experience has epistemic efficacy with respect to judgements of taste and, given epistemic relativism, whenever there is a change in the epistemic perspective of a subject, the gustatory experience that counted as evidence from her previous epistemic perspective loses its epistemic efficacy within her new perspective. Thus, in the case of taste we never have a situation in which two epistemically relevant, competing pieces of information coexist within the same perspective. As a result, the only epistemic effect that a piece of information (which would typically act as an overrider) can have in the taste domain is that of spoiling whatever former evidence a subject had of any epistemic relevance.

Second, there is no possibility of a genuine underminer. Given the primacy of experience, the only kind of information that has epistemic relevance is the subject's gustatory experience, so any other evidence that the subject may acquire, including the information that something might have interfered with her previous gustatory experience in such a way as to alter her GRs, has no epistemic force. IA2 is thus blocked. 


\section{Forthcoming in the Canadian Journal of Philosophy}

\section{Alethic dualism}

Let us take stock. We have argued that there is at least one domain (taste) where, in virtue of its peculiar subjectivist and relativist metaphysics and epistemology, IAs fail. There, truth and justification are normatively indistinguishable. Thus, truth in the taste domain does not have a distinctively normative nature. This result is compatible with two further corollaries: (i) that truth is never distinctively normative; (ii) that truth is distinctively normative in other domains with a different metaphysics and epistemology. In fact, we believe that upshot (ii) obtains. The failure of the IAs is tied to local features of the domain of taste: when a domain does not exhibit these features, Normative Divergence holds. As a result, truth emerges as a normative property for those domains. This establishes a form of alethic dualism — or so we argue.

In particular, we defend two theses. First, that Normative Divergence holds in (at least) two domains. All we need to do is to show that one of the IAs - for simplicity, we consider only IA1— goes through in the domains of arithmetic and astronomy. Second, we argue that the local soundness of IA1 has notable repercussions in the metaphysics of truth since it establishes a form of alethic dualism.

Let's call an argument an ordered couple with set propositions (its premises) and a proposition (its conclusion). An argument is sound just in case all of its premises are true and its conclusion logically follows from its premises. An argument-schema is sound relative to a domain $D$ just in case none of its instantiations in D gives rise to an unsound argument. Let us further stipulate that an argument-schema is locally sound just in case it is sound relative to (at least) one domain and unsound relative to (at least) another domain. The local soundness of an argumentschema entails that it is sound relative to some but not all domains. Finally, an argument-schema is globally sound just in case it is sound relative to all domains. 


\section{Forthcoming in the Canadian Journal of Philosophy}

Our claim is that the taste domain is a counterexample to the global soundness of the IAs. Since all taste propositions are immune to epistemic neutrality, IA1 is unsound there. Analogously, since the J-Links fail for all taste propositions, IA2 is unsound relative to the taste domain. However, relative to some other domains the step of Normative Divergence in IA1 goes through. This opens the possibility that IA1 is locally sound. In fact, we now show that IA1 is locally sound by showing that Normative Divergence holds in the domains of arithmetic and astronomy. To accomplish this, it suffices to show that for each of these domains there is at least one proposition satisfying epistemic neutrality.

It is uncontroversial that in many domains the epistemology and metaphysics we outlined for the taste domain is inadequate. As a matter of fact, in many domains epistemic neutrality is common and thus Normative Divergence holds. Consider the following proposition:

(MOON) The mass of the Moon is approximately $7.35 \cdot 10^{22} \mathrm{~kg}$.

One might ignore what the mass of the Moon is and thereby be in a position of epistemic neutrality with respect to MOON. However, we take it that it is undeniable that, as a matter of fact, MOON is true. Hence, Normative Divergence holds for such a case. Consider now the following proposition from the domain of arithmetic:

(PRIME) Primes become less common as they become larger. ${ }^{23}$

A subject might ignore the fact that primes become less common as they become larger since she/he might lack any procedure for assessing the truth of PRIME. In this respect, this subject would be in

\footnotetext{
${ }^{23}$ PRIME is an intuitive formulation of the Prime Number Theorem, which describes the asymptotic distribution of the prime numbers among the positive integers. A first elementary proof-i.e., a proof that can be carried within first-order Peano Arithmetic — was given by Atle Selberg in 1949.
} 


\section{Forthcoming in the Canadian Journal of Philosophy}

a position of epistemic neutrality with respect to PRIME. However, it is undeniable that, again, as a matter of fact, PRIME is true.

Thus, IA1 is sound relative to these two domains. This has notable repercussions for the metaphysics of truth. It establishes that there are domains with different truth properties: one with a normative nature (arithmetic and astronomy), the other with a non-normative nature (taste). This suffices to establish that there are at least two metaphysically distinct truth-properties and thus to justify a version of alethic dualism.

\section{From alethic dualism to ecumenical alethic pluralism via the scope problem}

Alethic dualism establishes a new way of developing a pluralist framework based on the coexistence of a normative property and non-normative property. Since pluralists have typically excluded the possibility of having a non-normative truth property — arguing only for a plurality of normative truth properties - alethic dualism constitutes a new way of arguing for pluralism, while also being an interesting position in its own right. In this section, we explain how alethic dualism can be integrated within a more general pluralistic framework. This establishes Ecumenical Alethic Pluralism. We achieve this by relying on what is considered to be the main argument in favour of alethic pluralism: the so-called scope problem..$^{24}$

The scope problem is based on the observation that there is variability in the epistemological and metaphysical features of domains. Moreover, this variability is symptomatic of a further variability in the truth properties of those domains. Consider, for example, the astronomical domain. There, it is intuitive to think that our true beliefs concern mind-independent objects (such as planets), which causally interact with us. These features make it highly plausible to think of truth in astronomy

\footnotetext{
${ }^{24}$ Lynch (2009, 32-6, 41-9).
} 


\section{Forthcoming in the Canadian Journal of Philosophy}

in terms of a correspondence theory of truth. ${ }^{25} \mathrm{On}$ this understanding, MOON is true because it is in a relation of causal correspondence to the mind-independent fact that the Moon is approximately $7.35 \cdot 10^{22} \mathrm{~kg}$.

When considering arithmetic, some of the features mentioned in relation to astronomy do not (uncontroversially) apply. In particular, it is implausible to think of numbers as objects with which we have a causal relation. This difficulty is highlighted by the well-known "Benacerraf's dilemma" ${ }^{26}$ Hence, causal correspondence is arguably inadequate when it comes to modelling truth in arithmetic. Indeed, PRIME is not true in virtue of our being in a causal relation with natural numbers. Among the possible models for arithmetical truth, a promising one is coherence with a set of axioms-e.g., Wright $(1998,234-36)$. On this model, the truth of PRIME consists in its being derivable from the axioms of Peano Arithmetic. ${ }^{27}$

The scope problem is thus an argument for the existence of a plurality of domain-specific truth properties. In particular, the previous remarks give us reason to think that the (normative) truth properties operating in, respectively, astronomy and arithmetic are different. If we add this result to alethic dualism, we have reason to think that there are (at least) three different truth-properties: a non-normative one for the domain of taste; the normative property of causal correspondence for the domain of astronomy; and the normative property of coherence for the domain of arithmetic. Note, moreover, that this pattern can be replicated in relation to other domains. That is to say, the scope problem — in tandem with variations in the metaphysics and epistemology of other domains—can deliver a variety of truth properties bearing both a normative and non-normative nature.

\footnotetext{
${ }^{25}$ E.g., Lynch (2009, Ch. 3, and Ch. 7).

${ }^{26}$ Benacerraf (1973).

${ }^{27}$ Coherence with the axioms of PA is just one model of truth in arithmetic that provides a metaphysically more acceptable account than correspondence. Of course, we do not wish to claim that this is the only, or even the best, model of truth for arithmetic: we just want to provide an example of a viable alternative to an account of truth that is widely considered inadequate for arithmetic.
} 


\section{Forthcoming in the Canadian Journal of Philosophy}

We have thus shown how to establish EAP. This form of pluralism is wider in scope than those hitherto developed in the literature to the extent that it includes (at least one) non-normative truth property. The following chart illustrates where to locate EAP within the current debate on the metaphysics of truth:

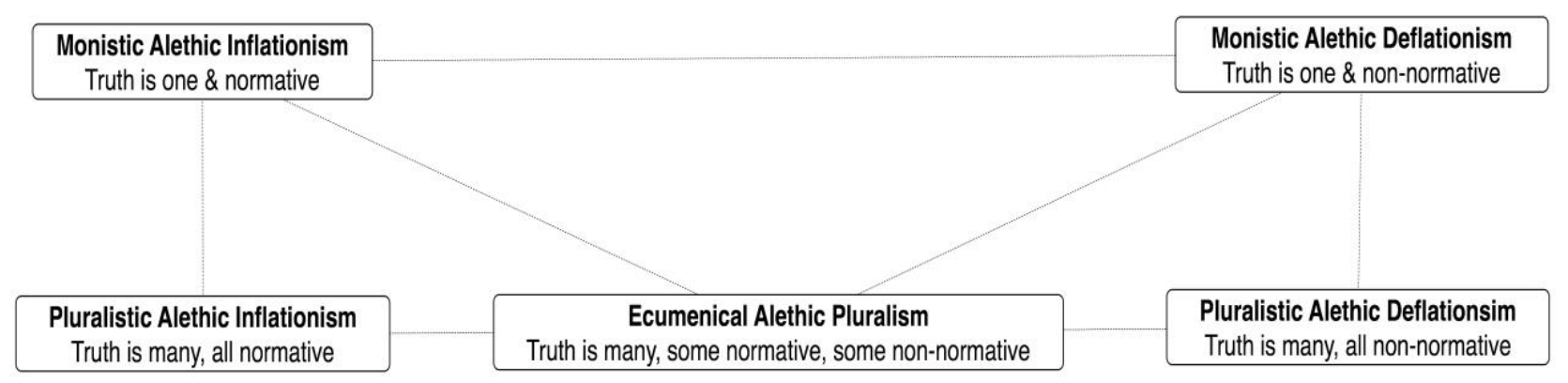

Figure 1. Truth: a new theoretical landscape.

An important issue requiring further scrutiny relates to how far EAP can go in its ecumenism. Those domains in which truth is non-normative are potential candidates for being domains whereby truth is locally deflationary. Once we take on board EAP, nothing excludes the possibility that the nonnormative truth property (or properties) permitted in the framework is (are) purely deflationary. Such a possibility has thus far been regarded as a form of heresy within the pluralist camp, and we think that the reason for such inflationary dogmatism is the unanimous endorsement of the global soundness of IAs. However, to comprehensively demonstrate the possibility of a local deflationary truth more needs to be done. In particular, we need to show not only that the IAs fail locally, but also that other important inflationary challenges fail. ${ }^{28}$ This is material for further work.

\section{Locating ecumenical alethic pluralism within the alethic pluralism debate}

\footnotetext{
${ }^{28}$ Four of them are prominent: i) the so-called Success Argument_Putnam (1978), Damnjanovic (2005); ii) the Semantic Argument-Bar-On, Horisk and Lycan (2000), Patterson (2005); iii) the Indeterminacy Argument-Horwich (2005), Field (2009); iv) the Axiological Argument-Horwich (2006), Lynch (2009) and Ferrari (2018).
} 


\section{Forthcoming in the Canadian Journal of Philosophy}

Before concluding, let us first consider two issues at the core of the pluralist debate, which have not yet been dealt with in developing our proposal, and which could further help to locate EAP within the current debate. The first (issue \#1) has to do with how to conceive of the truth concept within the EAP framework. The second (issue \#2) concerns what model(s) of the relation between the truth concept and truth properties best fits our proposal.

With regard to issue \#1, the most successful models of alethic pluralism developed thus far in the literature ${ }^{29}$ provide an analysis of the concept of truth in line with the so-called network analysis. ${ }^{30}$ On this approach, the concept of truth is characterized by a collection of platitudes that connect it to a network of other concepts — such as belief, assertion, correctness, enquiry, etc.- - thus specifying the functional role that the truth concept plays within the network. ${ }^{31}$ This analysis ensures conceptual unity while allowing for variation at the level of truth properties - viz., those properties that can play the truth role in relation to different subject matters.

The network analysis is standardly understood as involving two stages. First, a set of core features (or, as they are typically termed in the literature, "platitudes") concerning the analysandum (e.g., truth) is assembled. ${ }^{32}$ This set provides a theory of the target concept by laying down its theoretical role. Second, in relation to the metaphysical commitments of the theory, it is argued that whatever satisfies the theoretical role defined by the core principles is an admissible realiser of the concept. As Nolan (2009) points out, both stages of the network analysis are open to interpretation. With regard to the first stage, core principles can be understood along a Strict Conception. This is to say that they are analytic to the concept and therefore non-negotiable. Other, less strict,

\footnotetext{
${ }^{29}$ E.g., Wright (1998), Lynch (2000), (2009), Pedersen (2010), and Edwards (2013).

${ }^{30}$ This methodology has been adopted by, e.g., Jackson (1998), Lewis (1970) and Wright (1998).

${ }^{31}$ Core principles about truth are generally taken to be tacit beliefs that folks have reflecting and systematizing their ordinary understanding of truth — e.g., Lynch $(2009,7-8)$ - or the philosophers' ordinary understanding of truth reached through a process of critical philosophical reflection-e.g., Wright (2013, 128-9).

${ }^{32}$ Examples of lists of core principles concerning the truth concept are in Wright (1998), and Lynch (2009).
} 


\section{Forthcoming in the Canadian Journal of Philosophy}

interpretations take the core principles either as conditional on the existence of the postulated entities-i.e., if there were Xs then X-core principles would be true-or by providing a more externalist understanding - e.g., $\mathrm{X}$ is defined as the entity to which experts intend to refer with ' $\mathrm{X}$ '. These different interpretations of the first stage come with different views of the second stage. The Strict Conception fits the idea that $\mathrm{X}$ is the entity satisfying the theoretical role as defined by all the core principles with no exceptions. Let's call this the Strict Requirement. The more one departs from the Strict Conception the more one can be flexible vis-à-vis the requirements for satisfying the theoretical role. If no entity perfectly satisfies the theoretical role defined by the core principles of $\mathrm{X}$, one might still have recourse to the following options: (i) to require satisfaction of most of the core principles about X; (ii) to require satisfaction of the most important core principles (after some weighing of them); (iii) or satisfaction of most of the important core principles (Nolan 2009: 269). ${ }^{33}$

EAP, as a form of pluralism employing the methodology of network analysis, has to say something in relation to the two aforementioned stages, in particular on the nature of the core principles-i.e., which are the core principles for truth and what is their status? There is furthermore the question of how to address so-called "locational problems" 34 in relation to truth—what are the requirements in order for a property to play the role defined by the core principles, and how flexible are they? A detailed account of how best to conceive of the network analysis within the EAP framework would require a dedicated project. Here we can only hint at what we take to be the most plausible strategy for tackling this complex set of issues. EAP allows for a truth property that is nonnormative. Most pluralist frameworks include among their core principles some normative principles. Take, for example, Lynch's Norm of Belief, according to which a belief is prima facie

\footnotetext{
${ }^{33}$ Wright (1998) holds onto both Strict Conception and Strict Requirement. Lynch $(2009,13)$ departs from the Strict Requirement.

${ }^{34}$ See Jackson (1998, 2-5).
} 


\section{Forthcoming in the Canadian Journal of Philosophy}

correct if and only if its content is true. ${ }^{35}$ Alternatively, take Wright's Contrast Platitude ${ }^{36}$, the idea that a proposition may be true without being justified, and vice versa, thereby securing the potential extensional divergence between truth and justification at the heart of the IAs. EAP is committed to denying that the truth-realiser in the domain of taste satisfies Contrast and Norm of Belief. Thus, either Contrast and Norm of Belief are not core principles in EAP, or EAP must reject the Strict Requirement. We conjecture that the most feasible strategy to adopt for an advocate of EAP is to at least retain Norm of Belief among the core principles, but then to reject Strict Requirement. The advocate of EAP should then argue that although the truth concept imposes some normative constraint on belief - as specified by Norm of Belief - in certain domains (e.g., that of taste) the best realiser of the core principles does not reflect this normative aspect and thus has a non-normative nature. The reasons for this are complex and have to do with issue \#2, to which we now turn.

Two models of how to understand the relationship between the conceptual and metaphysical components of alethic pluralism have been discussed in the literature. The first model—known as Strong Pluralism - maintains that there is one truth concept and a plurality of truth properties, each of which operates as the truth property for one or more domains, with no generic truth property applying to all domains. The second model-Moderate Pluralism-agrees with the first model on the analysis of the concept, but also maintains that in addition to the various domain-specific truth properties, there is a generic truth property operating across all discourses. In a phrase, truth is metaphysically both one and many. The exact mechanics of how unity and plurality are achieved at the metaphysical level depends on the view in question (for example whether we are talking about

\footnotetext{
${ }^{35}$ See Lynch $(2009,10)$, and Pedersen and Wright $(2013,109)$. Edwards (2013) assumes truth to be normative by taking seriously the analogy between truth and winning. We think that Wright's IAS's are the main reason for the widespread idea among pluralists that truth is normative.

${ }^{36}$ See Wright $(1998,60)$ and Edwards $(2013,113)$.
} 


\section{Forthcoming in the Canadian Journal of Philosophy}

disjunctivist pluralism, ${ }^{37}$ second order functionalism, ${ }^{38}$ manifestation pluralism, ${ }^{39}$ or simple determination pluralism) ${ }^{40}$ Thus, the question is: what is the best model for EAP?

As noted above, EAP has two options: either dropping one or both of Contrast and Norm of Belief (and other normative core principles), or abandoning the Strict Requirement. If the first option is chosen, EAP is compatible with all of the aforementioned models of alethic pluralism. However, this option has a drawback: the fewer core principles there are, the harder is to address the alethic locational problem, for there might be many candidates satisfying the alethic role, none of which can be singled out as the best. For this reason, it is better for EAP to endorse the second option by abandoning the Strict Requirement. Doing so has consequences on the availability for EAP of moderate models insofar as the generic truth property usually integrates, as essential to its nature, those normative features individuated by Norm of Belief and Contrast. Let us illustrate this with the most prominent example of a moderate model: Lynch's Manifestation Pluralism. If in manifestation pluralism Norm of Belief and Contrast, as well as other core principles ("core truisms" in Lynch's terminology), are essential features of generic truth, then there can be no domain where truth fails to have a normative nature since generic truth is immanent in every truth-realiser. ${ }^{41}$

Thus, on the basis of these brief remarks, we believe that EAP is more easily integrated within a strong pluralism framework. More, of course, needs to be said on this issue. Nevertheless, for the purposes of this paper we rest content having merely sketched how to locate EAP within the rather complex array of pluralist proposals. ${ }^{42}$

\footnotetext{
${ }^{37}$ Pedersen and Wright (2013).

${ }^{38}$ Lynch (2000).

${ }^{39}$ Lynch (2009).

${ }^{40}$ Edwards (2013).

${ }^{41}$ Analogous points can be made for Simple Determination Pluralism. It is less clear that the abandonment of Strict Requirement makes EAP incompatible with second-order functionalism and alethic disjunctivism.

${ }^{42}$ See Ferrari and Moruzzi (unpublished manuscript) for a detailed discussion of what we call "the integration challenge".
} 


\section{Forthcoming in the Canadian Journal of Philosophy}

\section{Conclusions}

In this paper, we have explored the possibility of developing an ecumenical form of alethic pluralism (EAP). We have considered two inflationary arguments mounted against the availability of a nonnormative truth property and thus, a fortiori, against the possibility of EAP. We have argued that given a certain metaphysics and epistemology of taste these arguments fail in that domain. This failure makes space for a non-normative truth property operating in the domain of taste. We have also argued that Wright's first Inflationary Argument (IA1) goes through in at least two domains, astronomy and arithmetic, whereby truth should be conceived as normative. This establishes what we have called Alethic Dualism, which can be seen as a novel way to argue for a form of pluralism based on the existence of two kinds of truth property: one normative, and another non-normative. Relying on the scope problem, as applied to the domains of astronomy and arithmetic, we have argued that these two domains do not share the same truth property. We have briefly suggested that whereas causal-correspondence seems the right kind of truth property in astronomy, something like coherence with the basic axioms of Peano Arithmetic might work better for arithmetic. This gives us a new form of pluralism: Ecumenical Alethic Pluralism. This is wider in scope than traditional forms of alethic pluralism insofar as it includes, among a variety of normative truth properties, a non-normative property. Finally, we briefly discussed how to locate this new form of alethic pluralism within the current debate. ${ }^{43}$

\footnotetext{
${ }^{43}$ Acknowledgement: This paper has benefitted enormously from exchanges with many colleagues and friends. We are especially grateful to: Elke Brendel, Stefano Caputo, Massimo Dell'Utri, Douglas Edwards, Patrick Greenough, Paul Horwich, Michael Lynch, Nikolaj Jang Lee Linding Pedersen, Eva Picardi, Gila Sher, Erik Stei, Joe Ulatowski, Giorgio Volpe, Chase Wrenn, Cory Wright, Crispin Wright and Jeremy Wyatt.
} 


\section{Forthcoming in the Canadian Journal of Philosophy}

\section{References}

Bar-On, D., C. Horisk, and W. Lycan. 2000. "Deflationism, Meaning and Truth-Conditions." Philosophical Studies 101 (1): 1-28.

Barnard, R. and J. Ulatowski. (Forthcoming) "Does anyone really think that ${ }^{\Gamma} \varphi{ }^{\top}$ is true if and only if $\varphi$ ?" Forthcoming in Advances in Experimental Philosophy of Logic and Mathematics, edited by A. Aberdein, and M. Inglis. London: Bloomsbury.

Beall, JC. 2013. “Deflated truth pluralism.” In Pedersen and Wright (2013, 323-38).

Benacerraf, P. 1973. "Mathematical truth.” Journal of Philosophy 70: 661-79.

Chan, T. ed. 2013. The Aim of Belief. Oxford: Oxford University Press.

Damnjanovic, N. 2005. "Deflationism and the success argument." Philosophical Quarterly 55 (218): 53-67.

Edwards, D. 2013. “Truth, Winning, and Simple Determination Pluralism.” In Pedersen and Wright $(2013,113-22)$.

Einheuser, I. 2008. "Three forms of Truth Relativism.” In Relative Truth, edited by M. GarcíaCarpintero, and M. Kölbel, 187-203. Oxford: Oxford University Press.

Ferrari, F. 2018. "The Value of Minimalist Truth.” Synthese 195: 1103-1125.

Ferrari, F. and S. Moruzzi. Forthcoming. "Deflating Truth about Taste." The American Philosophical Quarterly.

Ferrari, F. and S. Moruzzi, S. Unpublished Manuscript. "The Integration Challenge to Alethic Pluralism.”

Field, H. 2009. “This Magic Moment: Horwich on the Boundaries of Vague Terms.”, In Cuts and Clouds, edited by R. Dietz, and S. Moruzzi, S, 200-8. Oxford: Oxford University Press. 


\section{Forthcoming in the Canadian Journal of Philosophy}

Fine, K. 2005. Modality and Tense. Oxford: Oxford University Press.

Horwich, P. 1998. Truth. 2nd ed. Oxford: Oxford University Press.

Horwich, P. 2005. “The Sharpness of Vague Terms.” Chap.4 in Reflections on Meaning. Oxford: Oxford University Press.

Horwich, P. 2006. “The Value of Truth.” Noûs, 40 (2): 347-60.

Jackson, F. 1998. From Metaphysics to Ethics: A Defence of Conceptual Analysis. Oxford: Oxford University Press.

Kölbel, M. 2013. “Should We Be Pluralists about Truth?” In Pedersen and Wright (2013, 278-97).

Lewis, D.K. 1970. “How to Define Theoretical Terms.” Journal of Philosophy 67: 427-46.

Lynch, M. 2000. “Alethic Pluralism and the Functionalist Theory of Truth.” Acta Analytica 24: 195214.

Lynch, M. 2009. Truth as One and Many. Oxford: Oxford University Press.

Nolan, D. 2009. "Platitudes and Metaphysics." In Conceptual Analysis and Philosophical Naturalism, edited by D. Braddon-Mitchell, and R. Nola, 267-300. Cambridge (MA): MIT Press.

Patterson, D. 2005. "Deflationism and the truth-conditional theory of meaning." Philosophical Studies 124: 271-94.

Pedersen, N.J.L.L. 2010. “Stabilizing alethic pluralism.” Philosophical Quarterly 60 (238): 92-108.

Pedersen, N.J.L.L. and C.D. Wright, eds. 2013. Truth and Pluralism: Current Debates. Oxford: Oxford University Press.

Price, H. 1998. "Three Norms of Assertibility, or How the Moa became Extinct.” Nô̂s 32 (12): 24154.

Putnam, H. 1978. Meaning and the Moral Sciences. London: Routledge \& Kegan Paul. 


\section{Forthcoming in the Canadian Journal of Philosophy}

Spencer, J. 2016. "Relativity and Degrees of Relationality." Philosophy and Phenomenological Research 42 (2): 432-59.

Williamson, T. 2000. Knowledge and Its Limits. Oxford: Oxford University Press.

Wollheim, R. 1980. Arts and its Object. Cambridge: Cambridge University Press.

Wright, C.J. 1992. Truth and Objectivity. Cambridge(MA): Harvard University Press.

Wright, C.J. 1993. “Anti-Realism, Timeless Truth and Nineteen Eighty-Four." Chap.10 in Realism Meaning and Truth. 2nd ed. Oxford: Blackwell.

Wright, C.J. 1998. “Truth: A Traditional Debate Reviewed." Canadian Journal of Philosophy 28: $31-74$.

Wright, C.J. 2013. “A Plurality of Pluralisms.” In Pedersen and Wright (2013, 123-53).

Wright, C.J. Unpublished Manuscript. "Faultless Disagreement." 